\title{
Bullet in penis: uncommon site, unusual track and unexpected result
}

\begin{abstract}
Introduction: Isolated gunshot injuries to the penis are rare. Usually, these injuries are associated with the significant destruction of tissues. We report a case of penile bullet injury with a long track of bullet without causing significant trauma.

Case summary: 45 years male with a history of a gunshot fired from the left side of the hip with a retained bullet in the penis. On evaluation no history of hematuria, no difficulty in walking. On examination, entry wound was found on the left side of buttock with no other injury mark except bruise at the base of the penis. The bullet was seen in the distal part of the penis on X-ray pelvis. No hematuria was seen. Retrograde urethrogram was normal. Pelvic X-ray was normal except a retained bullet was seen in distal part of the penis. The bullet was removed from the penis under local anaesthesia. Postoperative period was uneventful.
\end{abstract}

Conclusions: Penile lesions from gunshot wounds shall be treated through an immediate surgical intervention, except in cases where there are only superficial injuries.
Volume 8 Issue I - 2020

\author{
Manjeet Kumar,' Kalpesh Mahesh Parmar, ${ }^{2}$ \\ Varinder Attri, ${ }^{3}$ Abhishek Thakur ${ }^{3}$ \\ 'Assistant Professor, Department of Urology, IGMC, Shimla, HP, \\ India \\ ${ }^{2}$ Assistant Professor, Department of Urology, PGIMER \\ Chandigarh, India \\ 3SSenior resident, PGIMER, Chandigarh, India
}

Correspondence: Manjeet Kumar, Assistant Professor, Department of Urology, IGMC, Shimla, HP, India, Email manjeetkumar.1014@gmail.com

Received: May 22, 2019 | Published: February 27, 2020

Keywords: bullet, penis, dartos, urethra

\section{Introduction}

Isolated gunshot injuries to the penis are rare. Usually, these injuries are associated with the significant destruction of tissues. They need to be immediately investigated to assess the extension of the lesion to reproductive organs and prevent complications, such as bleeding, infection, penile curvature, erectile dysfunction and urethral stenosis. ${ }^{1,2}$ The injury may be associated with scrotal wounds and urethra. We report a case of penile bullet injury with a long track of bullet without causing significant trauma.

\section{Case presentation}

45 years male with a history of a gunshot fired from the left side of the hip with a retained bullet in the penis. On evaluation no history of hematuria, no difficulty in walking. On examination, entry wound was found on the left side of buttock with no other injury mark except bruise at the base of the penis. The bullet was seen in the distal part of the penis on X-ray pelvis (Figure 1). No hematuria was seen. Retrograde urethrogram was normal. Pelvic X-ray was normal except the retained bullet was seen in the distal part of the penis (Figure 2). The bullet was removed from the penis under local anesthesia. Postoperative period was uneventful (Figure 3).

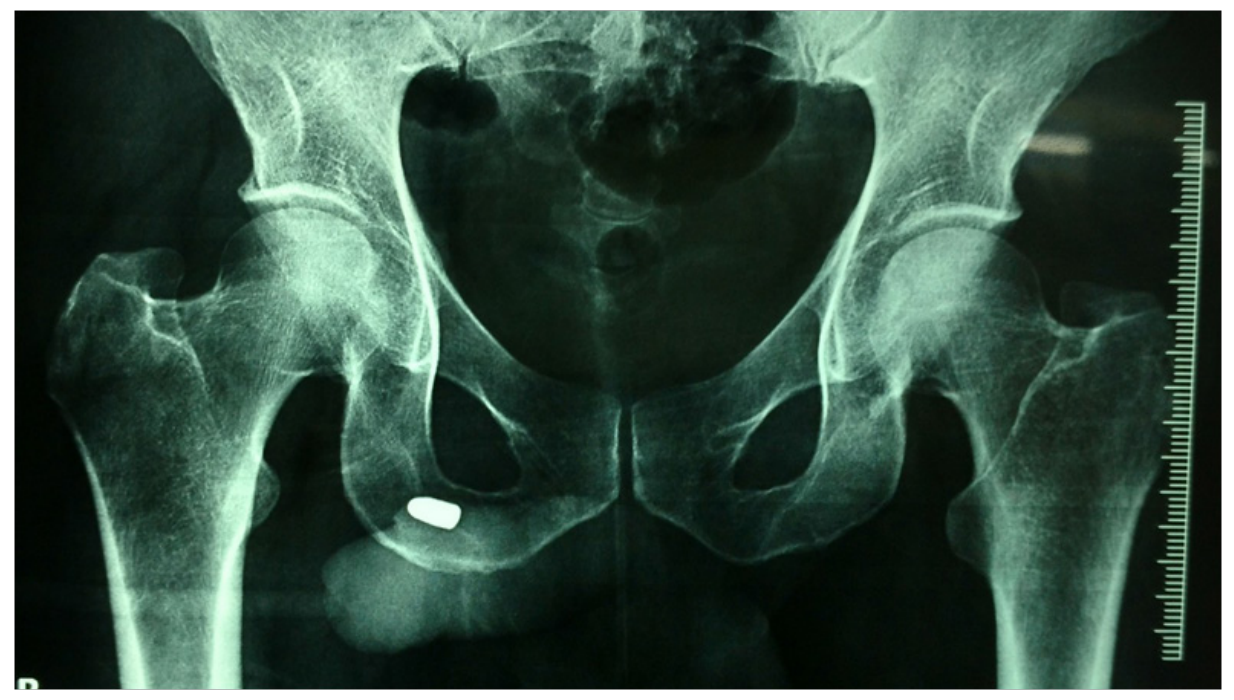

Figure I X-ray AP view showing bullet in penis. 


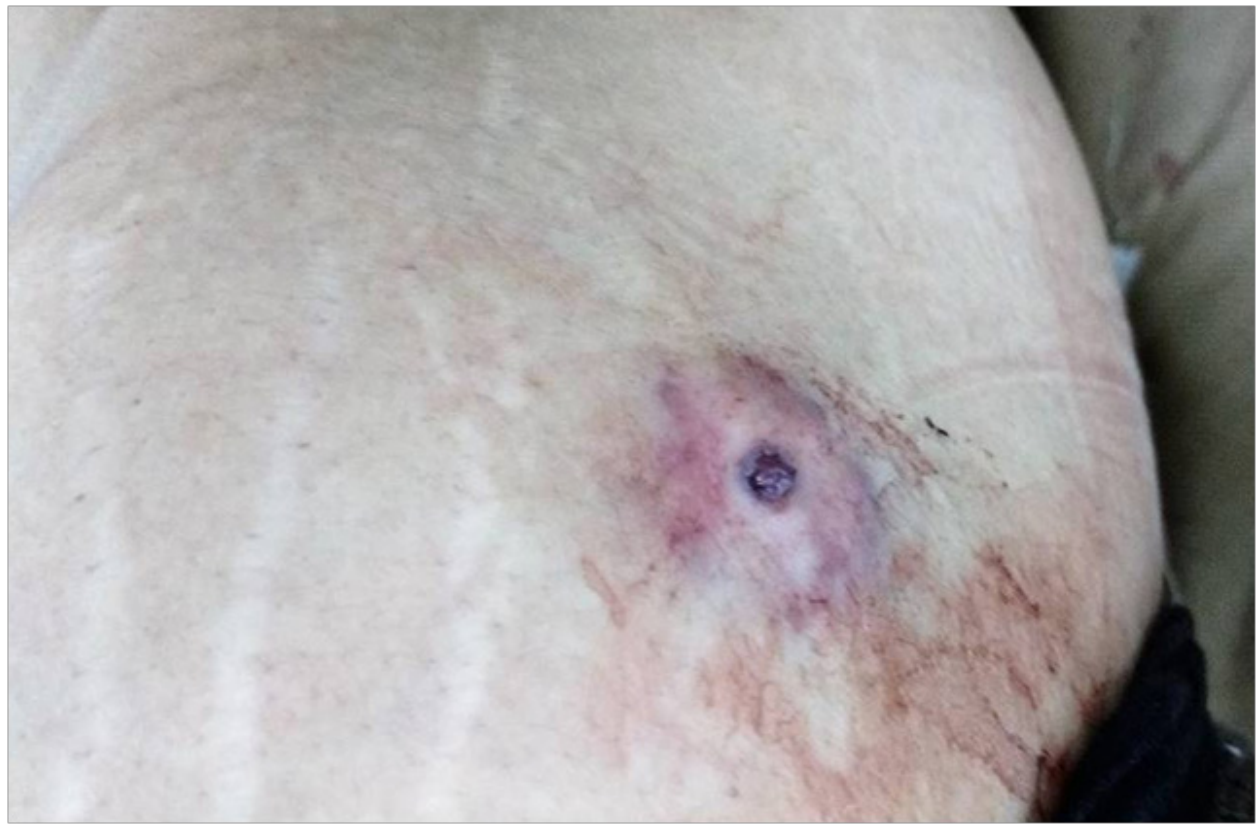

Figure 2 Entry wound in lateral thigh.

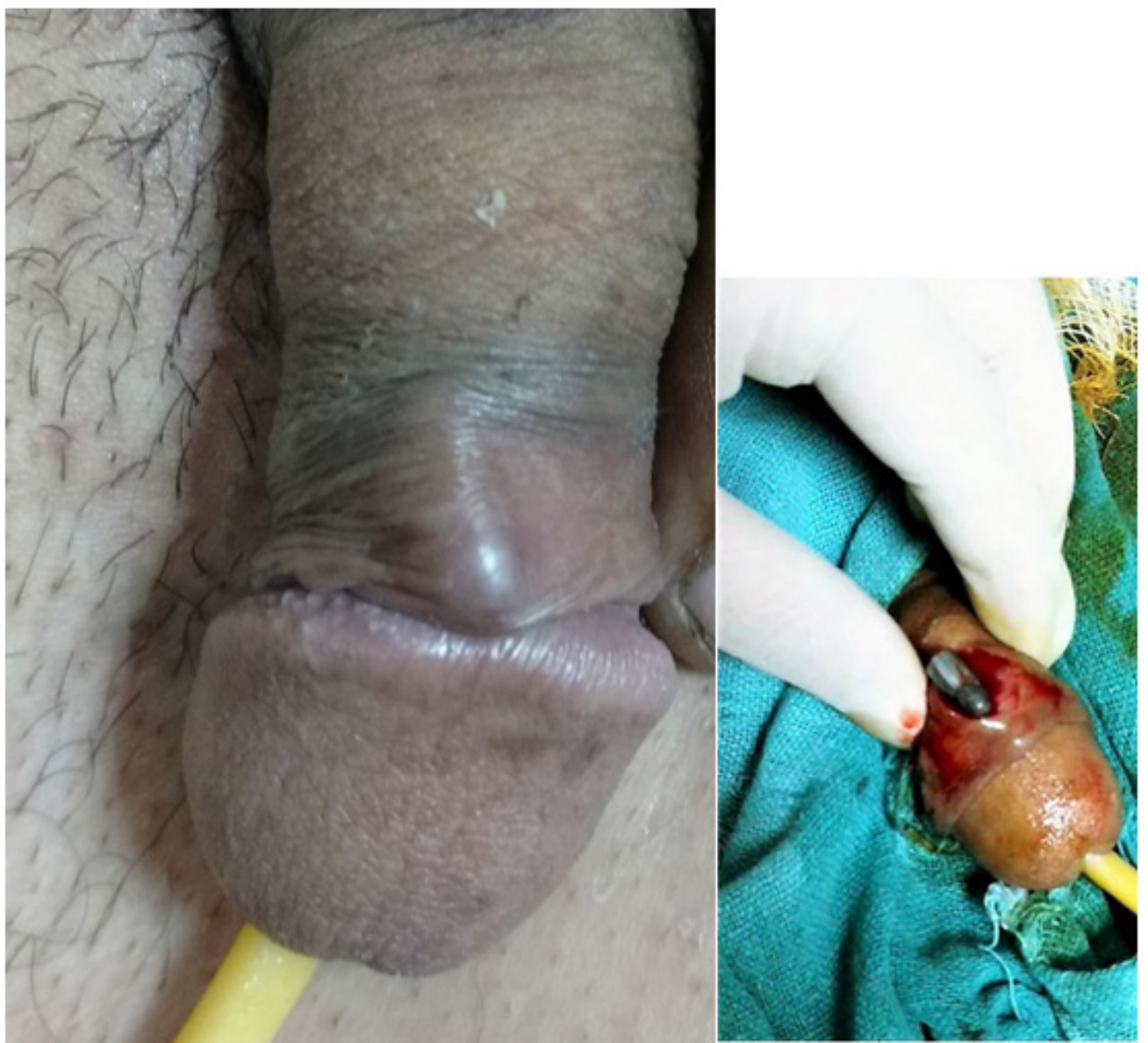

Figure 3 A) Bullet in penis visible through skin, B) Bullet removed under local. 


\section{Discussion}

Penile Gunshot injuries are seldom seen in India. The diagnosis and management depend upon the weapon caliber, type, and distance from a firearm. Success in the treatment of penile lesions from gunshot wounds depends on early surgical exploration, debridement of the wounded structures and primary lesion repair. ${ }^{2-4}$ Bullet injuries usually present with extensive trauma to tissue. Detailed history and examination is done. The physical examination of the Penis is best for diagnosis. Bullet injuries to Penis are associated with urethral injuries and Corporal injuries. ${ }^{5}$ For penetrating penile trauma, the physical examination is sufficient for evaluation. The patients having hematuria are evaluated with Retrograde urethrography. Patients having bullet injuries are explored and debridement with preservation of maximal tissue is done. Partial injuries of urethra are managed with careful catheterization and complete injuries Suprapubic catheterization is done. Patient having penetration into tunica albuginea are repaired primarily. ${ }^{6,7}$

Patients presented with injuries to genitalia are classified and managed according to the American Association of Trauma. Grade 1 injury includes Superficial injury, Grade 2 injuries involves Buck"s fascia breach without any associated injury. Grade III injuries involve Meatus, Glans, urethra and corpus cavernosum less than $2 \mathrm{~cm}$ which may require partial Penectomy with or without urethral and corpora repair. Grade IV injuries same as above with more than $2 \mathrm{~cm}$. Grade V injury severe injury requiring Penectomy. ${ }^{1,8}$ The use of the injury severity score from the American Association for the Surgery of Trauma (AAST) is being utilized to facilitate uniform treatment of genitalia lesions. ${ }^{1,8}$ According to this classification, superficial lesions and contusions are classified as the degree I and can be conservatively treated. Lesions classified as degree II (Buck fascia lacerations without tissue loss), degree III (cutaneous avulsion or laceration through glands and meatus, or urethral or cavernosum lesions less than $2 \mathrm{~cm}$ in area), degree IV (partial penectomy or urethral or cavernosum lesions more than $2 \mathrm{~cm}$ in area), and degree $\mathrm{V}$ (total penectomy) shall be treated with surgery. ${ }^{1,8}$ According to the literature, lesions of the urethra vary from 17 to $22 \%$ of the cases of penile lesions from gunshot wounds. ${ }^{1,2}$

Our case 2 nd-degree injury presented with a retained bullet without urethral injury. The patient was having an entry wound at the lateral hip. The bullet was lying in distal penile shaft within subcutaneous tissue. The patient was examined to rule out other injuries. Our injury was managed by incision over the distal penis with an incision over the skin and dartos. The bullet was removed and wound irrigated with normal saline. Dartos fascia is closed. Postoperatively patient was followed with smooth recovery.

\section{Conclusion}

Gunshot injuries to Penis are usually severe injuries which require exploration, however, our case was unique as Bullet was present in subcutaneous tissue without causing urethral injury. We removed the bullet in the emergency room without violating Corpora cavernosa. In Bullet injuries, it is important to remove Bullet from Penis and rule out urethral injury.

\section{Acknowledgments}

None.

\section{Conflicts of interest}

The author declares there is no conflict of interest.

\section{Funding}

None.

\section{References}

1. Morey AF, Metro MJ, Carney KJ, et al. Consensus on genitourinary Trauma: external genitalia. BJU Int. 2004;94(4):507-515.

2. Brandes SB, Buckman RF, Chelsky MJ. External genitalia gunshot wounds: a ten-year experience with fifty-six cases. J Trauma. 1995;39:266-271; discussion 271-272

3. Monga M, Moreno T, Hellstrom WJ. Gunshot wounds to the male genitalia. J Trauma. 1995;38(6):855-858.

4. Cline KJ, Mata JA, Venable DD, et al. Penetrating trauma to the male external genitalia. J Trauma. 1998;44(3):492-424.

5. Koifman L, Barros R, Junior RA, et al. Penile fracture: diagnosis, treatment, and outcomes of 150 patients. Urology. 2010;76(6):14881492

6. Summerton DJ, Djakovic N, Kitrey ND, et al. Guidelines on Urological Trauma. 2015.

7. Simhan J, Rothman J, Canter D, et al. Gunshot wounds to the scrotum: a large single-institutional 20 -year experience. BJU Int. 2012;109(11):1704-1707.

8. Moore EE, Malangoni MA, Cogbill TH, et al. Organ injury scaling VII: cervical vascular, peripheral vascular, adrenal, penis, testis, and scrotum. J Trauma. 1996;41(3):523-524. 